\title{
NA SELA DO CAVALO VERMELHO: A GUERRA PERPÉTUA COMO PRINCÍPIO DA INTELIGIBILIDADE HISTÓRICA NO CURSO EM DEFESA DA SOCIEDADE
}

Thatiana Victoria dos Santos Machado Ferreira de Moraes

Mestranda em filosofia (UFRJ)

Resumo: Michel Foucault, em seu curso "Em defesa da sociedade", esclarece o modo como se deu a produção de uma inteligibilidade histórica cujo centro é o discurso que rememora uma guerra perpétua entre 0 invasor e 0 invadido, retidos em um mesmo território e partes constituintes de uma mesma nação. Essa história traz à luz a guerra que dá origem à ordem e à lei estabelecidas, expondo a parcialidade da lei, sua ilegitimidade e seu passado de sangue.

Palavras-chave: Michel Foucault, Discurso, Sociedade, Racismo de estado.

"Havendo aberto o segundo selo, ouvi o segundo animal, dizendo: Vêm e vê! E saiu outro cavalo, vermelho; e ao que estava assentado sobre ele foi dado que tirasse a paz da terra e que se matassem uns aos outros; e foi-lhe dada uma grande espada."

São João de Patmos, Bíblia Sagrada, Ap. 6:3-4. 
Na na sela do cavalo vermelho :a guerra perpétua como princípio da inteligibilidade histórica no curso em defesa da sociedade - Thatiana Victoria dos Santos Machado Ferreira de Moraes

AnaLógos, Rio de Janeiro, v. 1, 2016, p. 97-104

O cavaleiro que vem na sela do cavalo vermelho é parte do passado dos homens desde tempos imemoriais: a guerra, aparentemente sempre tão ligada à negação da vida, possui sua positividade própria, particular estabelece fronteiras, institui governos, rearranja sociedades, introduz novas tecnologias, altera geografias. Mas, sendo a guerra parte do passado dos homens, ela não esteve sempre presente em sua história ou, se esteve, não se apresentou sempre sob a mesma configuração, ou com o mesmo protagonismo.

Ao longo dos séculos XVII e XVIII, um importante deslocamento acontece: um discurso que antes tinha como função principal recontar os feitos gloriosos e as vitórias dos reis, começa agora a rememorar batalhas antigas, guerras findas, não para cantar louvores à coroa, mas para encontrar nos combates passados os fundamentos da sociedade presente.

Em outras palavras, o discurso histórico mudará seu olhar sobre o passado: se até o princípio do século XVII, sua principal função seria dedicar-se a registrar os feitos mais dignos da realeza; durante o século XVIII, a história encontrará na guerra o núcleo das instituições políticas. Esta "nova" história revela que, ao avesso da ordem social aparentemente pacífica, estão instituições e verdades que foram impostas pelos vencedores da guerra.

Neste trabalho, buscarei, brevemente, explorar como essa inteligibilidade histórica - que retorna sempre à lama dos combates, que incessantemente reclama o que foi usurpado "no barulho da confusão da guerra" - é capaz de autorizar tanto o discurso do oprimido, do revolucionário, do destituído; como autorizar também aquilo que Foucault chamará de racismo de Estado e todas as suas consequências nefastas. Este texto é um exercício de leitura do curso ministrado pelo filósofo no Collège de France no ano de 1976, e por isso não buscarei trazer para a discussão outras bibliografias.

Michel Foucault, no curso Em defesa da sociedade, esclarece o modo como foi produzida uma inteligibilidade da história que tem como centro o discurso que rememora uma guerra perpétua, contínua, entre o invasor e o 
Na na sela do cavalo vermelho : a guerra perpétua como princípio da inteligibilidade histórica no curso em defesa da sociedade - Thatiana Victoria dos Santos Machado Ferreira de

Moraes

AnaLógos, Rio de Janeiro, v. 1, 2016, p. 97-104 invadido, retidos em um mesmo território e partes constituintes de um mesmo Estado. Essa história "rememora", traz à luz, relembra os abusos acontecidos no passado e a guerra que dá origem à ordem e à lei estabelecidas, expondo segundo este discurso - a parcialidade dessa lei, sua ilegitimidade, seu passado de sangue. A ordem civil, nos dirá Foucault, passa a ser lida como uma ordem de batalha, onde a espada demarcou o que seria justo e o que seria injusto, 0 legítimo e o ilegítimo. Sob uma mesma bandeira, restam múltiplas raças (no mínimo, duas), e cabe à raça vitoriosa ditar as leis sob as quais viverá o outro povo, esse outro que deve ser exterminado ou aceitar o domínio.

Na aula de 21 de janeiro de 1976, Foucault nos dirá que:

"A lei não nasce da natureza, junto das fontes frequentadas pelos primeiros pastores; a lei nasce das batalhas reais, das vitórias, dos massacres, das conquistas que tem sua data e seus heróis de horror; a lei nasce das cidades incendiadas, das terras devastadas; ela nasce com os famosos inocentes que agonizam no dia que está amanhecendo."

Assim, pelo menos, é como o século XVIII entenderá a história européia: como uma sucessão de massacres e destronamentos, de invasões e tomadas de poder, onde uma raça resta como a vitoriosa, coroada, enquanto outra é posta a parte, destituída, renegada. É uma sociedade fundada e eternamente perpassada pela guerra. Sob uma aparência ilusória e acidental de paz, uma guerra continuada e eterna, essencial, quase heraclítica - no sentido que, em sua destruiçãa, cria, funda as sociedades, e não deixa nunca de presentificar-se no interior do Estado, mesmo quando travestida de paz. Cabe à história ser, novamente nas palavras de Foucault, "esse discurso que tenta decifrar a guerra sob a paz." (p. 44).

Esse pode ser o grande questionamento de Em defesa da sociedade: como o discurso histórico se desloca de um louvor à Roma, isto é, do seu lugar de uma longa lista das realizações gloriosas dos reis, para o "instrumento geral de todas as lutas políticas", como chamaria Foucault. O trabalho de teóricos como Boulanvilliers, a quem Foucault atribui, entre outros, a constituição do 
Na na sela do cavalo vermelho :a guerra perpétua como princípio da inteligibilidade histórica no curso em defesa da sociedade - Thatiana Victoria dos Santos Machado Ferreira de Moraes

AnaLógos, Rio de Janeiro, v. 1, 2016, p. 97-104 discurso da guerra perpétua, foi encontrar esse conflito primeiro, inicial. Dirá Foucault na aula de 3 de março de 1976:

"A inteligibilidade histórica que Boulanvilliers queria introduzir, significa igualmente que se tratava não só de descobrir essa batalha nuclear fundamental e a maneira pela qual os outros combates derivam dela, mas que cumpria também localizar as traições, as alianças antinaturais, as astúcias de uns e as covardias dos outros, todas as preterições, todos os cálculos inconfessáveis, todos os imperdoáveis esquecimentos que haviam tornado possível essa transformação e, ao mesmo tempo, de certo modo, a adulteração dessa relação de força e desse enfrentamento fundamentais. ${ }^{2}$

Será uma multiplicidade de discursos que busca afirmar que o poder político não é a ruptura da dinâmica da guerra, mas a continuidade desta. $\bigcirc$ que isso significa, em termos concretos? Que cada instituição, cada lei e, em última instância, o projeto de sociedade na qual os Estados europeus foram fundados reflete a vitória de um grupo sobre o outro: são as instituições, leis e sociedades dos vencedores, que agora aparentam esquecer-se de seu estatuto como tais. A aparente imparcialidade e harmonia nacional esconde a subjugação de um grupo por outro.

Para que esse novo discurso histórico possa de fato se estabelecer, é preciso haver um deslocamento no objeto sobre o qual a história lança o seu olhar. Na aula de 11 de fevereiro, Foucault nos fala sobre o nascimento de um novo saber histórico, com a introdução de um novo sujeito histórico: a nação. Diz Foucault:

"Esse novo sujeito da história, que é ao mesmo tempo quem
fala na narrativa histórica e aquilo de quem fala essa narrativa
histórica, esse novo sujeito que aparece quando se descarta o
discurso administrativo ou jurídico do Estado sobre o Estado, o
que é? [...] é o que o vocabulário da época designa com a
palavra 'nação'."3 As nações, muitas, múltiplas, podem habitar um mesmo Estado, podem conviver reunidas somente sob uma aparência de paz. Marca-se então uma diferenciação entre a História do Estado - que é a narrativa da louvação de

\footnotetext{
${ }^{2}$ FOUCAULT, M. Op. cit., p. 160, 161.

${ }^{3}$ FOUCAULT, M. Op. cit., p. 112.
} 
Na na sela do cavalo vermelho :a guerra perpétua como princípio da inteligibilidade histórica no curso em defesa da sociedade - Thatiana Victoria dos Santos Machado Ferreira de Moraes

AnaLógos, Rio de Janeiro, v. 1, 2016, p. 97-104 Roma, da glória ininterrupta dos reis - e a História da Nação - marcada pela rememoração da invasão, pela divisão das raças, e pela luta na preservação de sua identidade em diferenciação ao outro.

Também na aula de 3 de março, Foucault diferencia a tática discursiva que o saber histórico se torna, disso que chamamos de ideologia. A história aparece, a partir do século XVII, como "arma discursiva", espada que pode ser desembainhada por um lado ou pelo outro. Em outras palavras, é uma construção argumentativa que não pertence a priori a grupo algum, a interesse específico algum, e sim um campo aberto para todos os confrontos políticos, instrumento e ferramenta, de modo generalizado. A história se torna essa arma no combate porque, segundo Foucault:

\begin{abstract}
"Trata-se primeiro, [...] de descobrir o conflito inicial [...] 0 núcleo belicoso do qual podiam derivar as outras batalhas, as outras lutas, todos os outros enfrentamentos, seja a título de consequência direta, seja por uma série de deslocamentos, de modificações, de reviravoltas nas relações de força. ${ }^{\prime 4}$
\end{abstract}

Com a defesa da teoria da guerra perpétua, com a construção de Boulainvilliers, se estabelece um campo de conhecimento, de saberes, denso cujas regras do jogo estão claras - no interior do qual haverão antagonismos, teorias, reflexões: tudo pois o campo epistemológico da história estará estabelecido. A história das nações como a história da guerra perpétua formula um campo epistemológico rigoroso, de pares opostos e de lutas extradiscursivas. Traz consigo a descrença na imparcialidade da lei e a denúncia de uma ordem que se enraíza em relações de força.

Essa história, essa nova história que compreende que tudo começou ali, no combate, não deixa esconder que aqueles no poder são os antigos inimigos, ou ainda, que os antigos inimigos vivem sob a mesma bandeira, por hora vencidos, mas prontos para atacar novamente. Foucault nos dirá, ainda na aula de 21 de janeiro: "Não há sujeito neutro. Somos forçosamente adversários de alguém". 
Na na sela do cavalo vermelho :a guerra perpétua como princípio da inteligibilidade histórica no curso em defesa da sociedade - Thatiana Victoria dos Santos Machado Ferreira de Moraes

AnaLógos, Rio de Janeiro, v. 1, 2016, p. 97-104

Essas mesmas narrativas históricas instituem no combate o caminho de vir-a-luz da verdade: uma verdade descentrada, que só pode ser conquistada com a consciência de estarmos em campo de batalha: de outra forma, estaremos acreditando na ilusão de paz que o adversário, essa figura tão nebulosa que pertence a uma outra raça, deseja que acreditemos. Todo discurso é um discurso histórico e político; toda verdade, forjada no interesse de um grupo.

O discurso centrado e imparcial é também o discurso do dominante, daquele que está vencendo a guerra, a quem interessa silenciar o clamor da batalha e aparentar uma suposta neutralidade do discurso corrente. Ter consciência de que a verdade não é neutra, mas arrancada de um campo de batalha, revela a precariedade desta verdade e seu caráter não somente provisório, mas também combativo.

É o que diz Foucault ao afirmar que "O pertencer essencial da verdade à relação de força, à dissimetria, à descentralização, ao combate, a guerra, está inserido neste tipo de discurso." (p. 45).

Pois bem, por um lado é possível vermos mais claramente os abusos sofridos, a imparcialidade, as violências continuamente naturalizadas. Por outro, o inimigo está entre nós, aqui, cantando o mesmo hino e hasteando a mesma bandeira, e ainda assim ele precisa ser exterminado, para purificação e proteção de nós, de nossa raça em oposição à outra raça. São ambas as consequências possíveis da guerra como inteligibilidade histórica, exatamente porque, como vimos, essa inteligibilidade histórica se firmará como um campo epistemológico que permite seus próprios embates discursivos. Se a origem dessa nova história estava na nobreza, não será só ela que usará a guerra como a legitimação de seus discursos.

Como podemos ver na aula de 28 de janeiro, o ideal revolucionário depende diretamente da contra-história reveladora dos abusos e das violências sofridas, da rememoração do combate. Nas palavras de Foucault, "A história de uns não é a história de outros". Esta rememoração é, ao mesmo tempo, uma 
Na na sela do cavalo vermelho :a guerra perpétua como princípio da inteligibilidade histórica no curso em defesa da sociedade - Thatiana Victoria dos Santos Machado Ferreira de Moraes

AnaLógos, Rio de Janeiro, v. 1, 2016, p. 97-104 negação profunda e determinada ao sujeito universal, à verdade objetiva. $O$ sujeito da verdade é só aquele que está se defendendo agora em uma posição de dominação. Mais radicalmente, podemos pensar que este argumento é o que permite questionar a hierarquização intrínseca à linguagem metafísica e ao logocentrismo - mas essa é uma discussão impossível de abordarmos neste curto trajeto.

Entretanto, essa guerra perpétua expõe uma luta de raças que se desenvolve como um eterno desdobramento da mesma raça sobre si mesma. Uma única raça que constantemente se divide em si mesma para justificar o combate perpétuo, a necessidade de retomada do poder, e o massacre do outro. Se existe um combate ativo, apenas dormente, apenas esquecido, mas ainda acirrado, torna-se imperativo defender a nação do risco de tornar-se a subraça, de ser contaminada pelo outro.

Esse "imperdoável esquecimento" que o século XVIII tentou remediar esquecimento da batalha, da luta que é a arché do Estado -, o século XIX tentará, naquilo que Foucault chama de "emburguezamento" da história, novamente apaziguar. Mas restam as marcas desse discurso, rastros dessa inteligibilidade, que ressurgem em palavras de ordem e em massacres no interior das populações, através desse corte, dessa qualificação e hierarquização, que é o racismo de Estado. Mas surgirá também nos levantes que constantemente relembram os abusos sofridos, os assassinatos impunes, as pilhagens que destituíram culturas inteiras.

Que esta peculiar interpretação histórica do fundamento da sociedade origine tanto a contra-história quanto 0 racismo de Estado parece surpreendente, mas como "arma discursiva utilizável", a guerra perpétua demonstrou ser, afinal, uma "faca de dois gumes", hora libertadora, hora extremamente opressora: o mesmo argumento que legitima massacres, denuncia violências. Nada mais apropriado: nas célebres palavras de Foucault em "Nietzsche, a genealogia e a história", "o saber não é feito para compreender, ele é feito para cortar". 
Na na sela do cavalo vermelho :a guerra perpétua como princípio da inteligibilidade histórica no curso em defesa da sociedade - Thatiana Victoria dos Santos Machado Ferreira de Moraes

AnaLógos, Rio de Janeiro, v. 1, 2016, p. 97-104

\section{CONSIDERAÇÕES FINAIS}

Por fim, gostaria de considerar esse "esquecimento" do qual nos vem alertar a história do século XVIII. Façamos uma pausa para pensarmos o quão nietzschiano é esse "esquecimento". É deste mesmo esquecimento que falará o filósofo: o apagamento que permite ocultar que a verdade é uma invenção, uma metáfora, e que pode muito bem ser, por isso mesmo, uma construção de um determinado grupo, de uma determinada raça, de acordo com seus próprios interesses. Esse esquecimento cruel - de que a verdade nunca é neutra, nunca é dada pelo mundo, mas pelo contrário, é retirada a fórceps -, o esquecimento do combate original, é o esquecimento do sangue perdido que não foi recuperado.

"[...] O feitor do sangue, Mark Ukaçierra, assim como tinham feito dezenas de predecessores, abria o registro e pesquisava página por página, coluna por coluna, através da rede das linhagens de sangue, até enfim achar algo: 'Sim, de fato vocês tem uma dívida de sangue. No mês tal, do ano tal, houve um débito que não foi saldado.' Nessas ocasiões, os olhos do feitor do sangue exprimiam uma severa repreensão por tão longo esquecimento. Davam a impressão de dizer: 'A paz de vocês tem sido uma mentira, ó desgraçados! "'15

\section{REFERÊNCIAS BIBLIOGRÁFICAS}

FOUCAULT, Michel. Em Defesa da Sociedade: Curso no Collège de France (1975-1976). São Paulo: WMF Martins Fontes, 2010. 